\title{
Characterisation of Tack for Uni-Directional Prepreg Tape Employing a Continuous Application-and-Peel Test Method
}

\author{
Andreas Endruweit ${ }^{1}$, Gabriel Choong ${ }^{1}$, Sayata Ghose ${ }^{2}$, Brice A. Johnson ${ }^{2}$, Douglas R. \\ Younkin $^{3}$, Nicholas A. Warrior ${ }^{1}$, Davide S.A. De Focatiis ${ }^{1}$ \\ ${ }^{1}$ Composites Research Group, Faculty of Engineering, University of Nottingham, University Park, Nottingham, \\ NG7 2RD, U.K. \\ ${ }^{2}$ The Boeing Company, Seattle, WA 98124, USA \\ ${ }^{3}$ Retired from The Boeing Company, St. Louis, MO 63166, USA \\ *corresponding author, e-mail andreas.endruweit@ nottingham.ac.uk, tel. +44 (0)115 9514037
}

\begin{abstract}
Employing a test method with coupled application and peel phases, tack was characterised for a UD prepreg tape. Different aspects of tack were explored by varying test parameters and material condition. In addition, different surface combinations were studied. In general, the test parameters, feed rate and temperature, affect the balance between cohesion within the resin and adhesion between resin and substrate. Exploring a range of parameters is required to understand the effect of viscoelastic resin properties on tack. The application pressure determines the true contact area between prepreg and substrate and hence affects tack. Changes in molecular mobility in the resin related to specimen conditioning, i.e. ageing or moisture uptake, result in maximum tack to occur at lower or higher feed rates, respectively. Differences in tack for different material combinations can be attributed to different molecular interactions at the contact interfaces and different resin distributions on the prepreg surfaces.
\end{abstract}

Keywords: A. Prepreg; B. Adhesion; E. Automated Fibre Placement

\section{Introduction}

Large composite components, in particular for aerospace applications, are frequently manufactured employing Automated Material Placement (AMP) processes, such as Automated Tape Laying (ATL) or Automated Fibre Placement (AFP). In AMP, robotic machinery applies layers of prepreg tape, typically from carbon fibre and partially cured thermoset resin, to the surface of a tool (at defined orientations) to form a laminate. The achievable laminate quality at given process parameters is related to the level of adhesion (tack) between the prepreg and the surface of the tool, between adjacent prepreg layers in a 
laminate, and between the prepreg and application rollers on the placement machinery. To prevent formation of defects in the uncured lay-up, such as wrinkling or bridging in the presence of local compressive or tensile forces in the prepreg tape, a sufficient level of prepreg-tool and prepreg-prepreg tack is required to withstand separating forces at the interfaces [1-3]. On the other hand, tack between the prepreg and application rollers needs to be minimal to prevent resin from building up on the rollers, or prepreg sticking to and eventually wrapping around the rollers, which would lead to failure of the lay-up process. Experimental characterisation of tack is a prerequisite for prediction of the behaviour of a prepreg during processing.

In published studies, tests with separate compression and tension stages are frequently employed for tack characterisation [1-10]. In the method described by Gillanders et al. [4], a single layer of prepreg is bonded to a specimen holder. Then, a flat metallic probe is pressed onto the exposed face of the prepreg at defined pressure and temperature for a defined period of time. When the probe is pulled off at a defined rate of separation, the strength of the bond between prepreg and probe is measured. Employing a similar method, Seferis and Meissonier [5] compressed a stack of prepreg layers between two flat parallel plates at a given pressure for a defined time interval to allow adhesion to form between adjacent layers, after the top and bottom layers had been bonded to the compression plates. The stack was subsequently loaded in tension at a defined rate. The total energy per unit volume required to separate the plies in tension is a measure for tack between prepreg layers.

An alternative method for tack testing is described by Banks et al. [11]. In a first stage, a prepreg strip is bonded to a metal substrate at defined temperature and compaction pressure for a defined interval of time. In a separate second stage, the prepreg is peeled off the substrate at a controlled angle and a prescribed rate using a floating roller set-up described in ASTM 3167 [12]. Tack is then characterised by the peel force per unit specimen width. Rao et al. [13] documented a similar approach, where a laboratory-scale fibre placement system is 
used in the first stage to bond the prepreg to the substrate at defined temperature, pressure and application speed.

A single-stage peel test for measurement of tack between a prepreg specimen and a rigid surface using a test fixture similar to the floating roller set-up was proposed by Crossley et al. [14]. This test differs from other methods in that the prepreg is bonded to and peeled from the substrate in a single continuous motion. It was argued that this is more reflective of AMP processes, since the time scale for bonding the prepreg to the substrate can be short in AMP, and bonding and peeling stages cannot be separated.

In this study, the continuous application-and-peel method proposed by Crossley et al. is employed to characterise the effect of different test parameters, surface combinations and prepreg conditions on measured tack for a carbon-fibre/epoxy prepreg. Results are related to observations reported in the literature based on tests with separate bonding and tension or peel stages. The aim is to further improve understanding of the fundamental phenomena governing tack and to give an indication on how to optimise process parameters for industrial AMP processes to obtain maximum lay-up performance at given prepreg properties.

\section{Material}

Tack was characterised for an aerospace grade uni-directional (UD) prepreg tape, made from intermediate modulus carbon fibres, at an areal density of $145 \mathrm{~g} / \mathrm{m}^{2}$, and a toughened epoxy resin system, at a resin content of $33 \%$ by weight. As typical for prepregs, the tape has two distinguishable faces. The inner face (when on a roll), is covered with a protective backing paper which is removed during the AMP process. The outer face, with no protective paper, is normally the face to be applied to the tool surface or another prepreg layer in an AMP process. In the following, the faces will be referred to as P ("paper") or N ("no paper"). Specimens tested here were from two different batches of material. For consistency, specimens in each series of tests were from the same batch. Batch 1 was used for all experiments except for those with humidity conditioning, where batch 2 was used. 
It was observed before that prepregs may show considerable variability in terms of local resin content and fibre alignment [15] and that resin distribution and surface morphology may vary between $\mathrm{P}$ face and $\mathrm{N}$ face [16]. Here, micrographs were taken to visualise the resin distribution on both prepreg surfaces. Images in Fig. 1 indicate that for both material batches, there tends to be more resin on the $\mathrm{P}$ face than on the $\mathrm{N}$ face of the prepreg. While both faces show irregular resin distribution for batch 1 , the difference between faces is more evident for batch 2 . The $\mathrm{N}$ face shows small-scale roughness related to the filament distribution beneath the surface of the thin resin layer. The thicker resin layer covering the $\mathrm{P}$ face shows roughness at a larger scale, which appears not to be related to the filament distribution.

\section{Experimental method}

Employing the continuous application-and-peel method discussed in detail by Crossley et al. [14], tack between a prepreg specimen and a rigid substrate is quantified as a peel force at a given specimen width. In short, rectangular prepreg specimens are laid up on rectangular steel substrates without any compaction. Substrates with specimens are then loaded into a test fixture (Fig. 2), which holds two pairs of stiff rollers, arranged horizontally. One pair of rollers provides guidance. In the second pair, the top roller (peel roller) is fixed, while springs apply a vertical force on the bottom roller (compaction roller). The compaction roller presses the prepreg against the substrate (and against the peel roller) at a controllable force. The fixture is mounted on the base of a universal testing machine. One end of the prepreg specimen is attached to the cross-head and load cell of the testing machine through a material clamp, such that the specimen is bent around the peel roller. In a tack test, the cross-head moves vertically at constant (adjustable) speed, which translates into a horizontal movement of specimen and substrate through the fixture. This results in the prepreg being bonded to and peeled from the substrate in a single continuous motion at a "feed rate" (or "peel rate") which corresponds to the speed of the cross-head movement. Here, the duration of compaction is 
inversely proportional to the feed rate. The tack force is derived from the tensile force at the load cell, which is recorded as a function of the cross-head displacement and is corrected for effects of friction in the set-up and bending of the specimen [14]. More detail is provided in the Appendix.

Crossley's original test method was extended to allow tack to be measured for material combinations other than prepreg-steel. The design of the test fixture was also modified [16] to allow the stiff peel roller to be replaced with a compliant roller made from stainless steel coated in polyurethane (PU), where the thickness of the PU coating corresponds to $1 / 3$ of the outer roller radius (which is $25 \mathrm{~mm}$ ) to obtain similar properties as rollers on AMP production machinery. Unless stated otherwise, tests in this study were carried out at a specimen width of $75 \mathrm{~mm}$, with a stiff peel roller, and at a compaction force of $100 \mathrm{~N}$.

The tack testing fixture can be used in an environmental chamber, allowing tack to be measured at different temperatures as well as different feed rates. An example of typical results is given in Fig. 3, where the error bars indicate standard deviations as a measure of the uncertainty resulting from scatter in the measured tensile force in each individual experiment. The data show that, at low measurement temperatures, a maximum in tack occurs at low feed rates. With increasing measurement temperature, the maximum in tack moves to higher feed rates.

For interpretation of the data, it is to be considered that prepregs show variability in local resin content and fibre alignment [15], which may result in significant variations in measured tack $[4,14]$. Local variability at a scale smaller than specimen dimensions affects the force readings during each individual test (see Appendix), which is reflected in the size of the error bars in Fig. 3. On the other hand, variability at a scale larger than specimen dimensions results in scatter of the average values of different tests, which may make it harder to identify general trends. Experimental data may also be affected by uncertainty in the test conditions, mainly in the temperature at the interface between prepreg and substrate, which is harder to control than feed rate and compaction force. Here, the temperature was monitored on the 
surface of the laid-up specimen prior to testing using a non-contact infrared thermometer, and tests were started when the measured temperature was within $\pm 1^{\circ} \mathrm{C}$ of the target temperature. During the tack tests, the relative humidity in the environmental chamber, was recorded but not controlled.

\section{Time-temperature superposition}

The principle of time-temperature superposition (TTS) implies that the viscoelastic behaviour of a polymer at a given temperature and frequency of dynamic loading can be related to that at another temperature through a shift in frequency of loading. This means that the modulus, $G$ (which can be either the storage modulus, $G^{\prime}$, or loss modulus, $G$ ”), at a temperature, $T$, and frequency, $\omega$, is equal to the modulus at a reference temperature, $T_{0}$, and frequency, $\omega a_{T}$, where $a_{T}$ is commonly referred to as shift factor:

$$
G(T, \omega)=G\left(T_{0}, \omega a_{T}\right)
$$

At a given $T_{0}$, the dependence of $a_{T}$ on temperature is commonly described by the Williams, Landel and Ferry (WLF) equation,

$$
\log _{10} a_{T}=\frac{-C_{1}\left(T-T_{0}\right)}{C_{2}+\left(T-T_{0}\right)}
$$

where $C_{1}$ and $C_{2}$ are empirical constants [18]. Applying the principle of TTS allows a master curve of the moduli as a function of the shifted frequency to be produced at a reference temperature by multiplying the measurement frequency by a shift factor according to Eq. (2). Shifting effectively extends the frequency domain beyond the measurable range.

While TTS has been applied to construct tack master curves for pressure-sensitive adhesives [19], Crossley et al. [20] demonstrated that the same principle can also be applied to tack of prepregs, using shift factors obtained from complementary rheological measurements on the resin system in the prepreg. This implies that the tack force, $F_{\mathrm{t}}$, 
measured at temperature, $T$, and feed rate, $r$, is equal to the tack force at the reference temperature, $T_{0}$, and the shifted feed rate, $r a_{T}$ :

$$
F_{\mathrm{t}}(T, r)=F_{\mathrm{t}}\left(T_{0}, r a_{T}\right)
$$

Employing this relation allows tack data at feed rates representative for AMP processes (typically in the order of $1 \mathrm{~m} / \mathrm{s}$ ), which are experimentally unachievable due to limitations on the cross-head speed on testing machines (typically in the order of $1 \mathrm{~m} / \mathrm{min}$ ), to be obtained through shifting of data acquired at low temperatures.

For the material characterised here, values for the parameters in Eq. (2) were obtained from oscillatory rheometry on a sample of neat resin, after it had been exposed to the same heat cycle as in the prepregging process. Isothermal frequency sweeps were carried out at increasing temperatures in the range between $0{ }^{\circ} \mathrm{C}$ and $70{ }^{\circ} \mathrm{C}$ (incremented by $10{ }^{\circ} \mathrm{C}$ ), at logarithmically increasing frequencies between $0.1 \mathrm{rad} / \mathrm{s}$ and $400 \mathrm{rad} / \mathrm{s}$, within the linear viscoelastic region. The moduli as a function of the frequency, measured at the respective temperatures, were shifted to other frequencies to achieve optimal overlap with data measured at a selected reference temperature. From the shift factors for different measurement temperatures, the parameters in the WLF equation were determined as $C_{1}=$ 10.098 and $C_{2}=74.086^{\circ} \mathrm{C}$ at $T_{0}=20^{\circ} \mathrm{C}$.

For the tack data shown as an example in Fig. 3, shifting the feed rates to $T_{0}=20^{\circ} \mathrm{C}$ gives the tack master curve in Fig. 4C. The figure suggests that shifted tack data, acquired in continuous application-and-peel tests, can be approximated by a Gaussian curve described by

$$
F_{\mathrm{t}}\left(T_{0}, r_{\mathrm{s}}\right)=F_{\mathrm{t} \max } \exp \left(-\left(\frac{\log \left(r_{\mathrm{s}} /(\mathrm{mm} / \mathrm{min})\right)-\log \left(r_{\mathrm{smax}} /(\mathrm{mm} / \mathrm{min})\right)}{w}\right)^{2}\right) \text {. }
$$

Here, $F_{\text {tmax }}$ is the maximum tack force, $r_{\mathrm{s}}=r a_{T}$ is the shifted feed rate, $r_{\mathrm{smax}}$ is the value of $r_{\mathrm{s}}$ at maximum tack, and $w$ indicates the width of the Gaussian curve. The coefficient of determination, $\mathrm{R}^{2}$, is given as a measure for the quality of the fit. While the selection of the fit function is purely phenomenological and not based on any physical model, $F_{\text {tmax }}$ and $r_{\text {smax }}$ in 
Eq. (4) are useful for quantitative description of tack behaviour. An implication of Eq. (2) is that the entire tack master curve can be shifted from $T_{0}$ to another reference temperature, $T_{1}$, where the feed rate at maximum tack increases for $T_{1}>T_{0}$ and decreases for $T_{1}<T_{0}$.

As discussed in the literature [5], prepreg tack is determined by adhesion between prepreg and substrate and cohesion within the resin in the prepreg. Adhesion depends on the physical and chemical properties of the surfaces and on the true contact area. For given viscoelastic properties of the resin, the true contact area is determined by the applied pressure, the duration of the compression, and the temperature. Cohesion within the resin in a prepreg depends only on its viscoelastic properties and is determined by the local strain rate and by temperature. Since, in the continuous tack tests discussed here, the prepreg is bonded to and peeled from the substrate in a single continuous motion, the general shape of the tack curve at any reference temperature (as in Figs. 4A to 4D) is determined by superposition of two competing effects:

- Adhesive strength increases with decreasing feed rate, since stronger bonds can form with increasing time of pressing the prepreg onto the substrate (which can be a steel plate [14] or another prepreg layer).

- Cohesive strength improves with increasing feed rate, since the flow stress increases with increasing strain rate at the point of peel (which is determined by the peel rate).

As a result, tack at lower feed rates (to the left of the maximum of the Gaussian curve) is limited by cohesive failure in bonds formed between the prepreg and the substrate, and long drawn-out resin threads may be observed at the interface ("fibrillation"). At higher feed rates (to the right of the maximum), tack is dominated by adhesive failure, and minimal or no formation of resin threads is observed between the surfaces. Modifying the viscoelastic resin properties by changing the molecular mobility in the resin can result in tack levels within cohesive failure or adhesive failure (or both) to change. Hence, the transition from adhesive to cohesive failure may move to a different feed rate. Changing the thickness of resin layers on the prepreg surfaces, and hence the strain rate, may affect tack levels in the region of 
cohesive failure. Hence, the transition between failure modes may change. Implications for the tack behaviour in terms of $F_{\mathrm{tmax}}$ and $r_{\mathrm{smax}}$ will be discussed in Section 5 .

As pointed out by Crossley et al. [20], the superposition of competing effects is not observed in compression-to-tension tests or in reported floating roller tests, where the duration of compression and the separation/peel rate are uncoupled, and where the compression and separation/peel stages may not be isothermal. However, the behaviour summarised in Figs. 4A to 4D is clearly related to observations reported in the literature. The decrease in tack at high feed rates, which results from a lack of time for bonds to develop, is consistent with the observations by Gillanders et al. [4], who found that tack measured in compression-to-tension tests increases with compression time, but quickly reaches saturation. Similarly, Seferis and Meissonnier [5] concluded that, at short compression time, tack is determined by adhesion, and otherwise by cohesion. Dubois et al. [10] observed fibrillation on the surface at low rates of separation, but not at high rates, which is consistent with a transition from cohesive to adhesive failure with increasing rate. Findings by Rao et al. [13] indicate that tack increases strongly with increasing temperature during compression of prepreg and substrate. This increase is related to improved molecular mobility at higher temperatures which facilitates (quick) formation of bonds and is consistent with the increase in feed rate at maximum tack with increasing temperature documented in Fig. 3. Similarly, Ahn et al. [6] reported that, at low temperature, tack is determined by surface effects (adhesion), whereas, at high temperature, it is determined by the viscoelastic resin properties.

\section{Results and discussion}

\subsection{Effect of surface combination}

Tack was measured for prepreg on different surfaces relevant to AMP processes:

- The original test procedure [14] was employed to measure tack between the prepreg and a polished and cleaned steel substrate, representing a flat tooling surface (neither release 
agent nor tackifier was applied). Either the $\mathrm{P}$ face, after the paper was removed, or the $\mathrm{N}$ face of the prepreg was in contact with the steel surface.

- The original procedure was adapted for prepreg-prepreg tack testing by bonding one prepreg layer onto a steel substrate ( $\mathrm{N}$ face in contact with substrate) using double-sided adhesive tape. Tests on aligned plies for the surface pairings $\mathrm{N}$ on $\mathrm{P}$ and $\mathrm{P}$ on $\mathrm{P}$ were then conducted as for measurement of prepreg-steel tack. To obtain valid results, the bond between the prepreg and the steel substrate provided by the double-sided adhesive tape needs to be stronger than tack between the prepreg layers. Unless stated otherwise, there was no indication of insufficient bond strength between the bottom prepreg layer and the steel substrate which might have affected the tests.

- Tack between fluorinated ethylene propylene (FEP), representing the surface coating of application rollers on material deposition machinery, and prepreg was measured employing a similar procedure as for measurement of prepreg-prepreg tack. A strip of FEP film at a thickness of $75 \mu \mathrm{m}$ and a width of $75 \mathrm{~mm}$ was attached to the load cell. It was then applied to and peeled from a prepreg layer bonded onto a steel substrate using double-sided adhesive tape (i.e. the FEP film was in contact with the $\mathrm{P}$ face of the prepreg).

For the five material combinations described above, tack was measured at (typically four) different temperatures and feed rates (as in the example in Fig. 3). The data were then shifted to a reference temperature $\left(T_{0}=20^{\circ} \mathrm{C}\right)$. To compare results for different surface pairings at $T_{0}$, values for the maximum tack force and the shifted feed rate at maximum tack were determined from fitted Gaussian curves according to Eq. (4).

The data listed in Table 1 indicate that the maximum tack force between the $\mathrm{P}$ face and the steel substrate (Fig. 4A) is $93 \%$ higher than that between the $\mathrm{N}$ face and the substrate (Fig. 4B). The shifted feed rate at maximum prepreg-steel tack is by a factor 2.5 higher for the $\mathrm{P}$ face than for the $\mathrm{N}$ face. This difference in observed tack can be attributed to different 
distribution and volume of resin on the two surfaces of the prepreg tape (Fig. 1, batch 1), which affect the true contact area and effective thickness of resin layers at the interface. As a result, both adhesion and cohesion are affected.

The data show also that maximum prepreg-prepreg tack is generally higher than maximum prepreg-steel tack (by factors between 2.5 and 5.5, depending on the face). The shifted feed rates at maximum tack are of the same order of magnitude as for prepreg-steel tack, lower than for face $\mathrm{P}$ on steel and higher than for face $\mathrm{N}$ on steel. Maximum tack is $10 \%$ lower for $\mathrm{P}$ on $\mathrm{P}$ (Fig. 4C) than for $\mathrm{N}$ on $\mathrm{P}$ (Fig. 4D). The feed rate at maximum tack is $14 \%$ higher for $\mathrm{P}$ on $\mathrm{P}$ than for $\mathrm{N}$ on $\mathrm{P}$. This weaker dependence of prepreg-prepreg tack on the surface combination (while the dependence on the surface combination is significant for prepregsteel tack) is consistent with the behaviour being dominated by the properties of the $\mathrm{P}$ face. Here, the resin volume tends to be greater than on the $\mathrm{N}$ face (Fig. 1), which would favour a greater contact area and thicker resin layer to form. In a laminate, the $\mathrm{N}$ face of a prepreg layer is normally in contact with the $\mathrm{P}$ face of a previously deposited layer. Hence, results for prepreg-prepreg tack reported in the following refer to this surface pairing.

In measurement of FEP-prepreg tack, only a low-level force (generally in the order of $1 \mathrm{~N}$ ) was observed (Fig. 4E). While virtually no tack could be detected at test temperatures of 20 ${ }^{\circ} \mathrm{C}, 30{ }^{\circ} \mathrm{C}$ and $40{ }^{\circ} \mathrm{C}$, residual resin was found sticking to the surface of the FEP film after the tests at a temperature of $50{ }^{\circ} \mathrm{C}$. This indicates that there must have been a transition from adhesive failure at the interface to cohesive failure within the resin. However, since a maximum in FEP-prepreg tack was hard to identify, the acquired data are not evaluated quantitatively here.

The differences in maximum tack observed for different surface pairings can be attributed to different interactions of polymer chains in the resin with surfaces of the substrates. The strength of developing bonds depends on both the chemical properties, which determine the type of bond (e.g. van der Waals forces), and physical properties (e.g. roughness) of the 
surfaces. Prepreg-steel tack is significantly higher than FEP-prepreg tack, since adhesion fails to develop on the FEP surface due to the specific surface characteristics. For prepreg on prepreg, polymer chains inter-diffuse between resin layers on the prepreg surfaces, effectively forming a single layer [21]. The resulting bonds tend to show increased strength compared to those between prepreg and a rigid substrate.

\subsection{Effect of out-time}

While prepregs are normally stored in a freezer to delay heat-induced progression of resin cure, they are exposed to "workshop conditions" (i.e. ambient temperature and humidity) for a finite period of time, typically referred to as "out-time", during laminate lay-up and prior to the curing process. To study the effect of out-time, $t_{\mathrm{out}}$, and the expected increase in the degree of cure [22] on prepreg tack, specimens were conditioned for 7 days and 14 days at a temperature of $(19.1 \pm 0.3){ }^{\circ} \mathrm{C}$ and a relative humidity of $(42.4 \pm 2.2) \%$. Top and bottom plies were conditioned separately before they were laid up for the tests. Specimens without out-time were exposed to the same (ambient) relative humidity at room temperature, albeit for a short period (a few hours) prior to being tested.

At different out-times, prepreg-prepreg tack ( $\mathrm{N}$ face on $\mathrm{P}$ face) was measured at a range of temperatures and feed rates. The measured data were shifted to a reference temperature $T_{0}=$ $20{ }^{\circ} \mathrm{C}$ using the same values of $C_{1}$ and $C_{2}$ for each out-time. Gaussian curves according to Eq. (4) were then fitted to the shifted experimental data (Fig. 5). Results characterising the tack behaviour, derived from the fitted Gaussian curves, are listed in Table 2. There is a trend for maximum tack to decrease with increasing out-time (by approximately $20 \%$ for $t_{\text {out }}=14$ days). More significantly, the feed rate at maximum tack decreases with increasing out-time of the prepreg specimens (by factors of approximately 5 for $t_{\mathrm{out}}=7$ days and 20 for $t_{\mathrm{out}}=14$ days). Here, an increasing degree of cure of the resin in the prepreg results in reduced 
molecular mobility and hence an increase in the time required for bonds to form between the plies during a tack test.

Ahn et al. [7] studied the behaviour of a prepreg as a function of ageing time. They reported an increase in tack (measured in compression-to-tension tests) with increasing degree of cure at high test temperatures and a decrease at low test temperatures. This is consistent with the observation that, at a reference temperature, the (shifted) feed rate at maximum tack decreases. It was also observed that out-time affects the prepreg surface characteristics [6], which may have an influence on development of adhesion and eventually on tack. At a given set of parameters for compression-to-tension tests, Dubois et al. [10] report a decrease in tack with increasing out-time. However, the effect was small since the maximum out-time was only $\sim 33$ hours. In floating roller tests, Banks et al. [11] observed low tack at short and long out-times, and a maximum in tack at intermediate out-times. This change in observed tack is consistent with a decrease in feed rate at maximum tack (as in Fig. 5). As a result, the maximum moves relative to a fixed feed/peel rate which may be to the left of the maximum in Fig. 5A and to the right of the maximum in Fig. 5C. If test conditions are kept constant for specimens with different out-times (as described by Banks et al.), the movement of maximum tack to another peel rate may not be detectable. An apparent change in tack with increasing out-time may be observed, which may be misleading since the behaviour over a wider range of peel rates is ignored.

In practice, the decrease in feed rate at maximum tack implies that, at a given temperature, the feed rate needs to be shifted to a lower value to obtain similar tack for a specimen with a given out-time as for a specimen with no out-time. Hence, it would be useful to describe the shift related to the specimen out-time by application of a factor to the feed rate, in a similar way to shifting applying TTS. This approach appears justified since out-time affects the molecular mobility in the polymer, as does temperature. While increasing temperature corresponds to increased mobility and hence a shift to higher feed rates, increasing out-time (degree of cure) corresponds to reduced mobility and a shift to lower feed rates. A similar 
approach was taken by Derail et al. [23] who determined additional shift factors to account for the effect of changes in the polymer properties, such as molecular weight, on peeling properties of adhesives.

\subsection{Effect of relative humidity}

To study the effect of $R H$ on tack, specimens were conditioned in sealed boxes prior to testing, following an approach described by Dubois et al. [10]. The conditioning boxes contained different saturated salt solutions corresponding to different (target) values of $R H$ at room temperature: The salts used here were magnesium chloride $\left(\mathrm{MgCl}_{2} ; R H=33 \%\right)$, potassium carbonate $\left(\mathrm{K}_{2} \mathrm{CO}_{3} ; R H=43 \%\right)$, and sodium bromide $(\mathrm{NaBr} ; R H=59 \%)$. Conditioning specimens at different $R H$ implies that they either absorb or desorb moisture, depending on whether the initial moisture concentration in the specimen is lower or higher than the moisture concentration in the boxes, until equilibrium is achieved. In preparation for the tack tests, the minimum conditioning time required for moisture levels in the prepreg specimens to stabilise and the maximum allowable period for exposure of conditioned specimen to ambient $R H$ (where a change in moisture content by no more than $20 \%$ from the initial condition was considered acceptable) were established. At fully exposed surface area, the corresponding times were 120 minutes and 6 minutes, respectively. Both plies in the layups were conditioned separately before the tests. The conditioning time in the order of 2 hours is not sufficient to cause a significant effect of out-time on the resin properties. After removing specimens from the boxes, top and bottom layers were brought into contact immediately to minimise the exposed surface area, and tests were carried out within 4.5 minutes (depending on the time required for the specimens to reach the test temperature in the environmental chamber) to minimise changes in moisture content through diffusion.

For illustration of differences in moisture content, a specimen of dimensions $30 \mathrm{~mm} \times 115$ $\mathrm{mm}$ (backing paper removed to fully expose surfaces) was conditioned at different levels of 
$R H$ at a temperature of $21^{\circ} \mathrm{C}$. The specimen was conditioned at $R H=33 \%$ first, then at $R H$ $=43 \%$, and finally at $R H=59 \%$ (for two hours at each level). Immediately after conditioning at each level, the specimen was weighed to determine the change in mass through moisture uptake. Results listed in Table 3 indicate the increase in moisture content in the specimen.

For specimens conditioned at different $R H$, prepreg-prepreg tack ( $\mathrm{N}$ face on $\mathrm{P}$ face) was measured at a range of temperatures and feed rates. The measured data were shifted to a reference temperature $T_{0}=20{ }^{\circ} \mathrm{C}$. To compare tack at different $R H$, Gaussian curves were fitted to the measured data (Fig. 6), and maximum tack and the feed rate at maximum tack were determined at $T_{0}$.

Results listed in Table 4 show that maximum tack at all three target values of $R H$ is significantly smaller than maximum prepreg-prepreg tack ( $\mathrm{N}$ face on $\mathrm{P}$ face) without humidity conditioning (Table 1) and that the maxima occur at higher feed rates. It is thought that this is related to a different batch of material being characterised here (batch 2) than in all other test series (batch 1). The resin distribution on the surfaces is more regular, and the layer on the $\mathrm{P}$ face is thicker, for batch 2 compared to batch 1 (Fig. 1), which may explain the observed difference in tack behaviour between batches. However, the general trends observed here are not affected.

The results show also that the target $R H$ has an effect on measured tack. This effect is small when $R H$ is increased from $33 \%$ to $43 \%$ (maximum tack is virtually unaffected, while the feed rate at maximum tack increases by $11 \%$ ) and more significant when $R H$ is increased from $33 \%$ to $59 \%$ (maximum tack increases by $20 \%$, while the feed rate at maximum tack increases by $89 \%$ ). The observed effect is related to plasticization of the resin upon moisture uptake, the fundamentals of which are discussed extensively in the literature, e.g. by Zhou and Lucas [24]. In general, higher $R H$, i.e. higher moisture content (Table 3), corresponds to 
higher level of plasticization. For illustration, the glass transition temperature, $T_{\mathrm{g}}$, was determined employing Differential Scanning Calorimetry (DSC) on neat resin. It was found to be approximately $3{ }^{\circ} \mathrm{C}$ higher for specimens conditioned at $R H=22 \%$ (at room temperature) than for specimens conditioned at $R H=76 \%$, which is an indicator for increasing level of plasticization. The effect of plasticization is similar to that of increasing temperature, i.e. the molecular mobility in the polymer is increased, and hence the maximum in tack is shifted to higher feed rates. The increase in maximum tack is likely related to an increased true contact area at a given compaction force, which may overcompensate a loss in resin cohesion resulting from plasticization.

At a given set of test parameters, Dubois et al. [10] observed a decrease in measured tack with increasing $R H$ in compression-to-tension tests. This may be a result of the maximum in tack moving to a higher separation rate (in analogy to the move to higher feed/peel rate observed here), which cannot be detected if test conditions are kept constant.

The increase in feed rate at maximum tack implies that, at a given test temperature, the feed rate needs to be shifted to a higher value to obtain similar or higher tack for a specimen with higher moisture uptake than for a specimen with lower moisture uptake. In analogy to the proposal for out-time shifting, this could be described by introducing an additional shift factor.

\subsection{Effect of compaction force and peel roller type}

The effects of the force applied through the compaction roller and of the properties of the peel roller on prepreg-prepreg tack ( $\mathrm{N}$ face on $\mathrm{P}$ face) were studied at a single temperature $(T$ $\left.=30{ }^{\circ} \mathrm{C}\right)$ and feed rate $(r=20 \mathrm{~mm} / \mathrm{min})$, selected as a combination near maximum tack. The compaction force was incremented in steps of $20 \mathrm{~N}$ in the range from $20 \mathrm{~N}$ to $160 \mathrm{~N}$. The data in Fig. 7 indicate that, for both peel rollers used here, the measured tack force converges 
to a limit value as the compaction force increases. A plausible empirical description of the dependence of the tack force, $F_{\mathrm{t}}$, on the compaction force, $F_{\mathrm{c}}$, is

$$
F_{\mathrm{t}}=F_{\mathrm{t} \infty}\left(1-\exp \left(-F_{\mathrm{c}} / F_{\mathrm{c}}^{*}\right)\right)
$$

where $F_{\mathrm{t} \infty}$ is the limit value of the tack force, and the constant $F_{\mathrm{c}}{ }^{*}$ is a measure of the rate of change in tack force with increasing compaction force. Fitting equations of this type to the experimental data indicates that results obtained using different peel rollers converge to the same limit value, and that convergence is faster (i.e. $F_{\mathrm{c}}{ }^{*}$ is smaller) for the compliant roller than for the stiff roller (Table 5).

To explain these observations, the difference between the total prepreg area compressed under the peel roller, i.e. the apparent contact area between prepreg layers, and the true contact area between the layers, which is smaller than or equal to the total compressed area, is to be considered. The general behaviour shown in Fig. 7 for each peel roller is related to flattening of the prepreg surfaces in the compressed area when the compaction pressure is increased. As a result, the true contact area between the prepreg layers increases in size, implying that the number of bonds which can form between the layers increases. Hence, the tack force increases with increasing compaction pressure. At high compaction pressure, the true contact area does not change if the pressure is increased any further. The tack force converges to a limit value, $F_{\mathrm{t} \infty}$, which depends on the resin properties only.

While it was not possible to quantify the true contact area experimentally for prepregprepreg contacts, trends for the dependence of the true contact area on the applied compaction pressure were determined based on a method proposed by Helmus et al. [16]. Using the tack test fixture, prepreg specimens with a width of $25 \mathrm{~mm}$ were applied to (but not peeled from) glass slides at defined compaction force. Based on analysis of micrographs taken from underneath the glass slides, the true contact area, which appears darker than other areas, was determined. The tests were conducted at a temperature of $21^{\circ} \mathrm{C}$ and a feed rate of $3 \mathrm{~mm} / \mathrm{min}$ (near maximum tack, see Table 1) using the stiff peel roller. Example data plotted 
in Fig. 8 indicate that (for the $\mathrm{N}$ face) the increase in true contact area with increasing compaction pressure follows a similar relation as described in Eq. (5), albeit with different constants.

Comparing results obtained using the two different rollers, deformation of the compliant roller implies that a given compaction force results in a larger apparent contact area (length of contact in feed direction) between the prepreg layers than for the stiff roller. Hence, the effective compaction pressure, which determines the true contact area, is smaller than for the stiff roller. On the other hand, the duration of compaction at a given feed rate is longer than for the stiff roller, i.e. there is more time for bonds to form in the true contact area between the layers. For the material characterised here, superposition of these effects results in a greater tack force at given compaction force when the compliant roller is used than when the stiff roller is used. As a result, convergence is faster for the compliant roller, i.e. the value of $F_{\mathrm{c}}{ }^{*}$ is smaller. Because of the compliance of the prepreg layers, the total contact area depends on the compaction pressure even if the stiff peel roller is used. However, this dependence is weak compared to the dependence for the compliant roller. Any potential effect of the (unknown) local pressure distribution in the apparent contact area is not considered here.

An increase in compaction force at given resin properties has a similar effect as an increase in molecular mobility at given compaction force. Both result in an increased true contact area, i.e. stronger adhesion, at a given feed rate. While only a single combination of $T$ and $r$ was studied here, it can be inferred that the feed rate at maximum tack increases with increasing $F_{\mathrm{c}}$.

In compression-to-tension tests reported in the literature, tack was generally found to increase with compaction pressure and duration of its application $[4,6,10]$. Gillanders et al. observed similar convergence behaviour as in Fig. 7 for pressure-sensitive adhesive tape [4], which they attributed to a strong dependence of tack on the true contact area. This 
complements observations by Seferis and Meissonnier, who concluded that, at short contact time and at low pressure, tack is determined by adhesion, otherwise by cohesion [6].

\subsection{Effect of ply orientation}

In aerospace applications, laminates are typically produced from UD prepreg tapes at different orientation of the individual layers. The effect of the inter-ply angle on prepregprepreg tack was studied for the pairing $\mathrm{N}$ face on $\mathrm{P}$ face, at a single temperature $\left(T=30^{\circ} \mathrm{C}\right)$ and feed rate $(r=50 \mathrm{~mm} / \mathrm{min})$, selected as a combination near maximum tack. For practical reasons, the top layer in prepreg-prepreg tack testing, i.e. the layer that is applied to and peeled from the layer bonded onto the steel substrate, always has to be oriented at $0^{\circ}$ (fibres need to be continuous in this layer to prevent it from disintegrating during the peel test). On the other hand, the bottom prepreg layer can be bonded onto a steel substrate at any angle, $\alpha$. Here, the orientation of the ply bonded onto the substrate relative to the ply being peeled was varied between $0^{\circ}$ and $90^{\circ}$ (incremented by $15^{\circ}$ ).

The measured tack increases continuously with increasing inter-ply angle (Fig. 9). However, for inter-ply angles greater than $60^{\circ}$, adhesion between the bottom prepreg layer and the substrate failed, while there was still adhesion between both prepreg layers. For these cases, the measured (apparent) tack represents a lower bound of the real tack, since tack between prepreg layers was stronger than adhesion provided by the double-sided adhesive tape which failed. Tack measured at an inter-ply angle of $60^{\circ}$ was found to be approximately $33 \%$ higher than tack for aligned plies (Table 6). For an inter-ply angle of $45^{\circ}$, which is particularly relevant since laminates frequently contain $\left[0^{\circ}, 45^{\circ}, 90^{\circ}\right]$ lay-up sequences, tack increased by $20 \%$ compared to $\alpha=0^{\circ}$. While tack at different inter-ply angles was characterised only for one combination of $T$ and $r$, measured tack increases beyond the peak of the Gaussian curve at $\alpha=0^{\circ}, F_{\operatorname{tmax}}=(22.41 \pm 0.72) \mathrm{N}$. Hence, the observed increase in 
tack with increasing inter-ply angle must be a result of increasing peak tack rather than movement along a Gaussian curve relative to a constant peak.

A possible explanation could be a difference in true contact area between layers for different inter-ply angles. The total volume of air inclusions at the interface between the prepreg layers (between areas of true contact) would also depend on the inter-ply angle. According to a theory of tackiness proposed by Gay and Leibler [25], this would result in different levels of cavitation affecting tack during ply separation. Another possible explanation could be different effective thickness of the resin layer at the interface for different inter-ply angles, which would result in a different strain rate but also in a different feed rate at maximum tack.

However, Seferis and Meissonnier [5] observed no significant effect of the inter-ply angle on measured tack in compression-to-tension tests (where the effects discussed above would also occur). Assuming that, in their results, the influence of the inter-ply angle was not obscured by other effects, this suggests that the dependence of tack on the inter-ply angle observed here could be specific to the continuous application-and-peel method. While the difference in observations is not fully understood at present, it can be speculated that the geometry of ply separation, which is different in peel than in tensile loading of parallel flat plies, results in different outcomes.

\section{Conclusions}

Employing a continuous test method with coupled application and peel stages, tack was measured for a UD prepreg tape at different feed rates and temperatures to explore the viscoelastic response of the material. Using parameters obtained in complementary rheometry on neat resin, tack master curves were produced by shifting data to a reference temperature applying TTS. It was found that the dependence of tack on the shifted feed rate can be approximated by Gaussian curves. The shape of the curves, which is specific to the 
continuous application-and-peel test method, is a result of the competing effects of increasing cohesion within the resin and decreasing adhesion between resin and substrate with increasing feed rates. Maximum tack and feed rate at the maximum derived from fitted Gaussian curves can be used to quantitatively describe tack behaviour.

For prepreg on a steel substrate, measured maximum tack and feed rate at the maximum were higher for the face of the prepreg originally covered with a backing paper than for the uncovered face, which was attributed to different resin distributions on both prepreg surfaces. As a result of different molecular interactions at prepreg-steel and prepreg-prepreg contact interfaces, maximum prepreg-prepreg tack is significantly higher than maximum prepregsteel tack, while the feed rate at the maximum is in the same order of magnitude. Virtually no tack was observed between FEP and prepreg, although there was evidence of adhesion at high measurement temperatures.

With increasing out-time of specimens, maximum prepreg-prepreg tack decreases slightly, while the feed rate at maximum tack decreases. Conditioning specimens at increased levels of relative humidity results in an increase in both maximum prepreg-prepreg tack and feed rate at the maximum. Both observations are related to changes in molecular mobility in the resin, which decreases with increasing out-time, because of an increase in the degree of cure, and increases with increasing moisture uptake due to plasticization of the resin.

Increasing the compaction force results in increasing prepreg-prepreg tack which converges to a limit value. The convergence is faster for a compliant peel roller than for a stiff peel roller. Both effects are related to increasing true contact area and duration of compression of the prepreg surfaces. Furthermore, it was found that increasing the inter-ply angle results in increasing maximum prepreg-prepreg tack. While this effect is not fully understood, it is thought to be related to the geometry of the peel test.

Where applicable, observations were compared with results presented in the literature. Taking into account that literature data were obtained employing tests with separate application and tension or peel stages, they are generally consistent with the interpretation of 
the tack phenomenon presented here. Importantly, it can be concluded that acquiring data at a single set of test parameters may lead to misinterpretation of the results. Since tack depends strongly on the temperature- and rate-dependent viscoelastic properties of the resin, measurement at a range of test parameters is required to fully explore tack behaviour.

Preliminary manufacturing trials for aerospace components indicated that using the tack master curves produced here for selection of process parameters, in particular machine temperature and feed rate, to obtain appropriate tack values can indeed improve the prepreg lay-up performance. Even though the relation between measured tack values and formation of defects in AMP processes is not straightforward, this observation demonstrates the usefulness of the presented work for practical application.

\section{Acknowledgements}

Samuel Kelly and Matthew Elsmore contributed to the construction of the test devices employed in this study. The authors gratefully acknowledge the support received from procurement and contracts of the University of Nottingham, UK, and Boeing Research and Technology, Seattle, USA.

\section{Appendix}

During a tack test, the face of the prepreg that is in contact with the peel roller is covered with protective paper (an added layer if this is the $\mathrm{N}$ face) to prevent the material from sticking to the roller. The face of the prepreg that is in contact with the substrate is partially covered by a layer of protective paper (either part of the paper is removed from the $\mathrm{P}$ face or a layer is added on the $\mathrm{N}$ face), such that the specimen surface is exposed on a defined length (here: $80 \mathrm{~mm}$ ). If prepreg-prepreg tack is tested, the face of the bottom layer (P face) in contact with the other layer is exposed on the same length to match the top layer.

The additional paper layer separates the prepreg from the substrate during the first phase of the test. In this phase, the force for overcoming friction in the system and for bending of the prepreg (which is also determined by the viscoelastic resin properties) and of two layers 
of protective paper is measured. Once the specimen has moved sufficiently far for the exposed part of the prepreg surface to be in contact with the substrate (second phase of the test), the measured force corresponds to the sum of the friction force in the system, the force for bending of the prepreg and one layer of protective film and the tack force. Hence, the tack force can be calculated from the difference of forces in phases 2 and 1, plus the force for bending of one layer of paper. Two examples of raw data acquired in tack tests are shown in Fig. A1, where two force levels corresponding to phases 1 and 2 can clearly be identified. The diagrams show some scatter in the recorded force, which is related to small-scale local variations in material properties. The dip in the measured force at the transition between the phases is a result of a discontinuity in total thickness where the separating layer of paper ends. The figure also shows that the characteristics of raw data for prepreg-steel tack and prepreg-prepreg tack are the same. The force in phase 2 is higher for prepreg-prepreg tack than for prepreg-steel tack.

In an additional test, a single layer of backing paper is laid up on a steel substrate, and the force for bending of the paper around the peel roller is measured. The average tack force, $\left\langle F_{\mathrm{t}}\right\rangle$ is calculated from the average forces in phases 1 and $2,\left\langle F_{1}\right\rangle$ and $\left\langle F_{2}\right\rangle$, and the average force for bending of the backing paper, $\left\langle F_{\mathrm{b}}\right\rangle$, according to

$$
\left\langle F_{\mathrm{t}}\right\rangle=\left\langle F_{2}\right\rangle-\left\langle F_{1}\right\rangle+\left\langle F_{\mathrm{b}}\right\rangle
$$

The standard deviation of the tack force, $\sigma_{\mathrm{t}}$, is calculated from the standard deviations of the forces in phases 1 and 2, $\sigma_{1}$ and $\sigma_{2}$, and the standard deviation of the force for bending of the backing paper, $\sigma_{b}$, according to

$$
\sigma_{\mathrm{t}}=\sqrt{\sigma_{2}^{2}+\sigma_{1}^{2}+\sigma_{\mathrm{b}}^{2}}
$$

This quantity is a measure of the local scatter in the measured force. For illustration, values corresponding to the data plotted in Fig. A1 are listed in Table A1. 


\section{References}

[1] Beakou A, Cano M, Le Cam JB, Verney V. Modelling slit tape buckling during automated prepreg manufacturing: A local approach. Compos Struct, 2011; 93(10): 2628-2635.

[2] Wohl C, Palmieri FL, Forghani A, Hickmott C, Bedayat H, Coxon B, Poursartip A, Grimsley B. Tack measurements of prepreg tape at variable temperature and humidity. In: Composites and Advanced Materials Expo (CAMX 2017). Orlando, September, 2017.

[3] Belhaj M, Hojjati M. Wrinkle formation during steering in automated fiber placement: Modeling and experimental verification. J Reinf Plast Comp, 2018; available online 25.01.2018.

[4] Gillanders AM, Kerr S, Martin TJ. Determination of prepreg tack. Int J Adhes Adhes, 1981; 1(3): 125-134.

[5] Seferis JC, Meissonnier J. Development of a Tack and Drape Test for Prepregs Based on Viscoelastic Principles. Sampe Quart, 1989; 20(3): 55-64.

[6] Ahn KJ, Seferis JC, Pelton T, Wilhelm M. Deformation Parameters Influencing Prepreg Tack. Sampe Quart, 1992; 23(2): 54-64.

[7] Ahn KJ, Peterson L, Seferis JC, Nowacki D, Zachmann HG. Prepreg Aging in Relation to Tack. J Appl Polym Sci, 1992; 45(3): 399-406.

[8] Putnam JW, Seferis JC, Pelton T, Wilhelm M. Perceptions of Prepreg Tack for Manufacturability in Relation to Experimental Measures. Sci Eng Compos Mater, 1995; 4(3): 143-154.

[9] Putnam JW, Hayes BS, Seferis JC. Prepreg process-structure-property analysis and scale-up for manufacturing and performance. J Adv Mater, 1996; 27(4): 47-57.

[10] Dubois O, le Cam JB, Beakou A. Experimental Analysis of Prepreg Tack. Exp Mech, 2010; 50(5): 599606.

[11] Banks R, Mouritz AP, John S, Coman F, Paton R. Development of a new structural prepreg: characterisation of handling, drape and tack properties. Compos Struct, 2004; 66(1-4): 169-74.

[12] ASTM D3167-10. Standard test method for floating roller peel resistance of adhesives. ASTM International, West Conshohocken: PA, 2010.

[13] Rao S, Umer R, Thomas J, Cantwell WJ. Investigation of peel resistance during the fibre placement process. J Reinf Plast Comp, 2016; 35(4): 275-286.

[14] Crossley R.J, Schubel PJ, Warrior NA. The experimental determination of prepreg tack and dynamic stiffness. Compos Part A - Appl Sci, 2012; 43(3): 423-434.

[15] Potter K, Langer C, Hodgkiss B, Lamb S. Sources of variability in uncured aerospace grade unidirectional carbon fibre epoxy preimpregnate. Compos Part A - App Sci, 2007; 38(3): 905-916.

[16] Helmus R, Kratz J, Potter K, Hubert P, Hinterhölzl R. An experimental technique to characterize interply void formation in unidirectional prepregs. J Compos Mater, 2017; 51(5): 579-591.

[17] Endruweit A, Ghose S, Johnson BA, Kelly S, De Focatiis DSA, Warrior NA. Tack testing to aid optimisation of process parameters for automated material placement in an industrial environment. In: $21 \mathrm{st}$ International Conference on Composite Materials (ICCM 21). Xi'an, August, 2017.

[18] Williams ML, Landel RF, Ferry JD. The Temperature Dependence of Relaxation Mechanisms in Amorphous Polymers and Other Glass-Forming Liquids. Phys Rev, 1955; 98(5): 3701-3707.

[19] Benedek I, Feldstein MM. Fundamentals of Pressure Sensitivity. Boca Raton: CRC Press, 2008.

[20] Crossley RJ, Schubel PJ, De Focatiis DSA. Time-temperature equivalence in the tack and dynamic stiffness of polymer prepreg and its application to automated composites manufacturing. Compos Part A Appl Sci, 2013; 52: 126-133.

[21] Voyutskii SS, Vakula VL. The role of diffusion phenomena in polymer-to-polymer adhesion. $J$ Appl Polym Sci, 1963; 7(2): 475-491.

[22] Kim D, Centea T, Nutt SR. In-situ cure monitoring of an out-of-autoclave prepreg: Effects of out-time on viscosity, gelation and vitrification. Compos Sci Technol, 2014; 102: 132-138.

[23] Derail C, Allal A, Marin G, Tordjeman P. Relationship between Viscoelastic and Peeling Properties of Model Adhesives. Part 1. Cohesive Fracture. J Adhesion, 1997; 61(1-4): 123-157.

[24] Zhou J, Lucas JP. Hygrothermal effects of epoxy resin. Part II: variations of glass transition temperature. Polymer, 1999; 40(20): 5513-5522.

[25] Gay C, Leibler L. Theory of Tackiness. Phys Rev Lett, 1999; 82(5): 936-939. 
batch 1
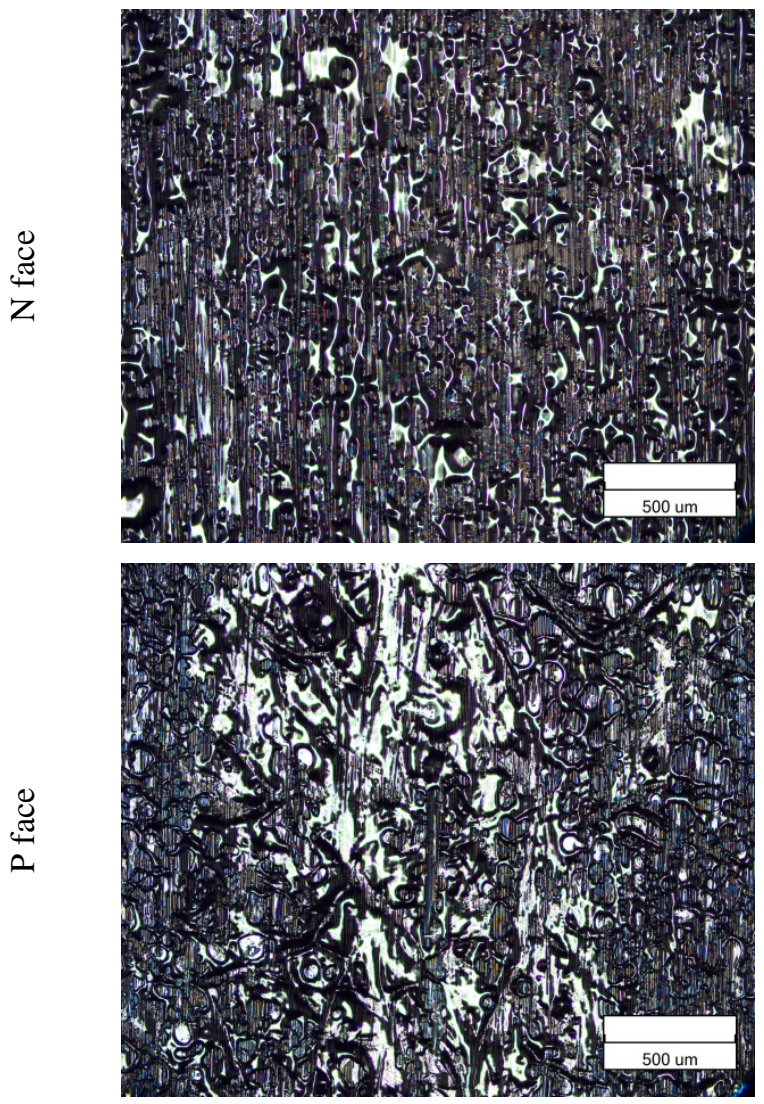

batch 2
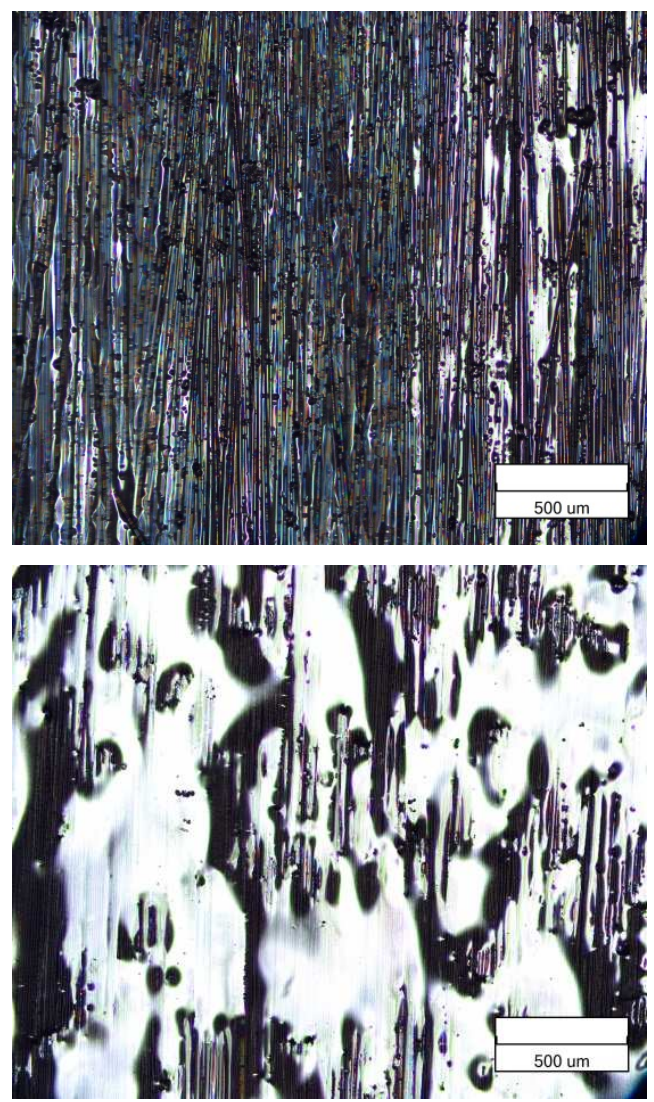

Figure 1. Micrographs of prepreg surfaces for both material batches; images were focused on the filament surfaces; resin on the material surface is visible as white areas. 


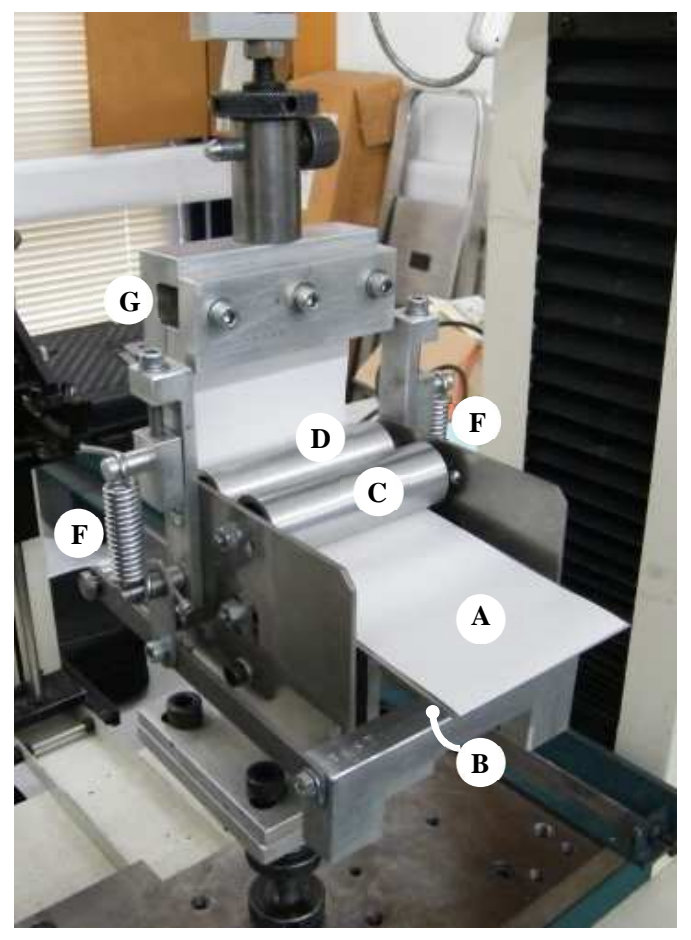

A: prepreg (with backing paper)

B: steel substrate

$\mathrm{C}$ : guide roller

D: peel roller

E: compaction roller

F: adjustable springs

G: material clamp

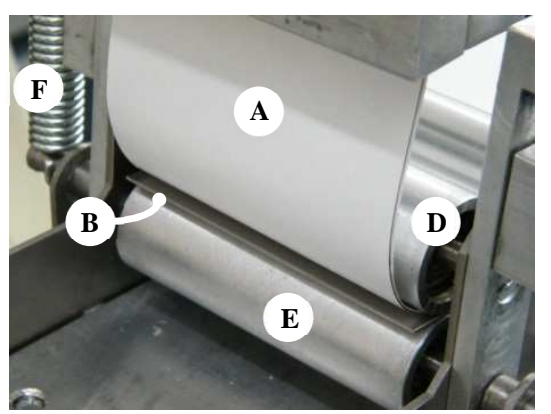

Figure 2. Tack test fixture as proposed by Crossley et al. [14].

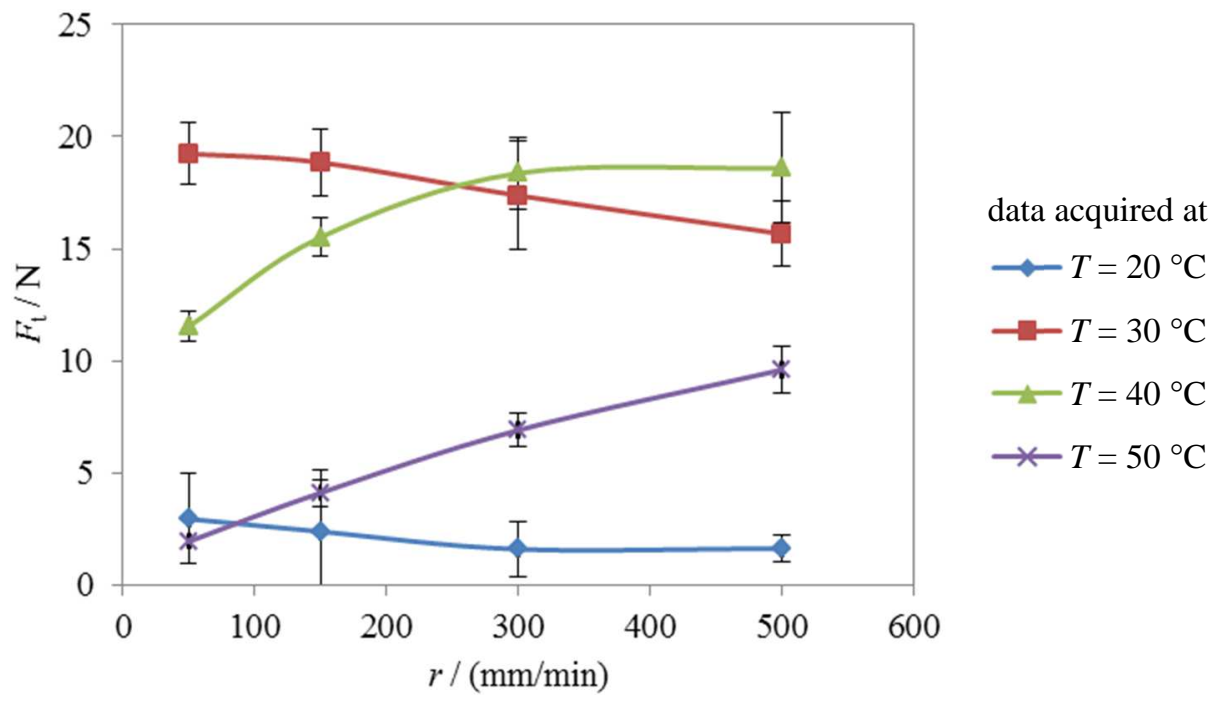

Figure 3. Prepreg-prepreg ( $\mathrm{P}$ face on $\mathrm{P}$ face) tack force, $F_{\mathrm{t}}$, acquired at different temperatures, $T$, and feed rates, $r$; average values and standard deviations are indicated; the lines interpolate between measured data points. 

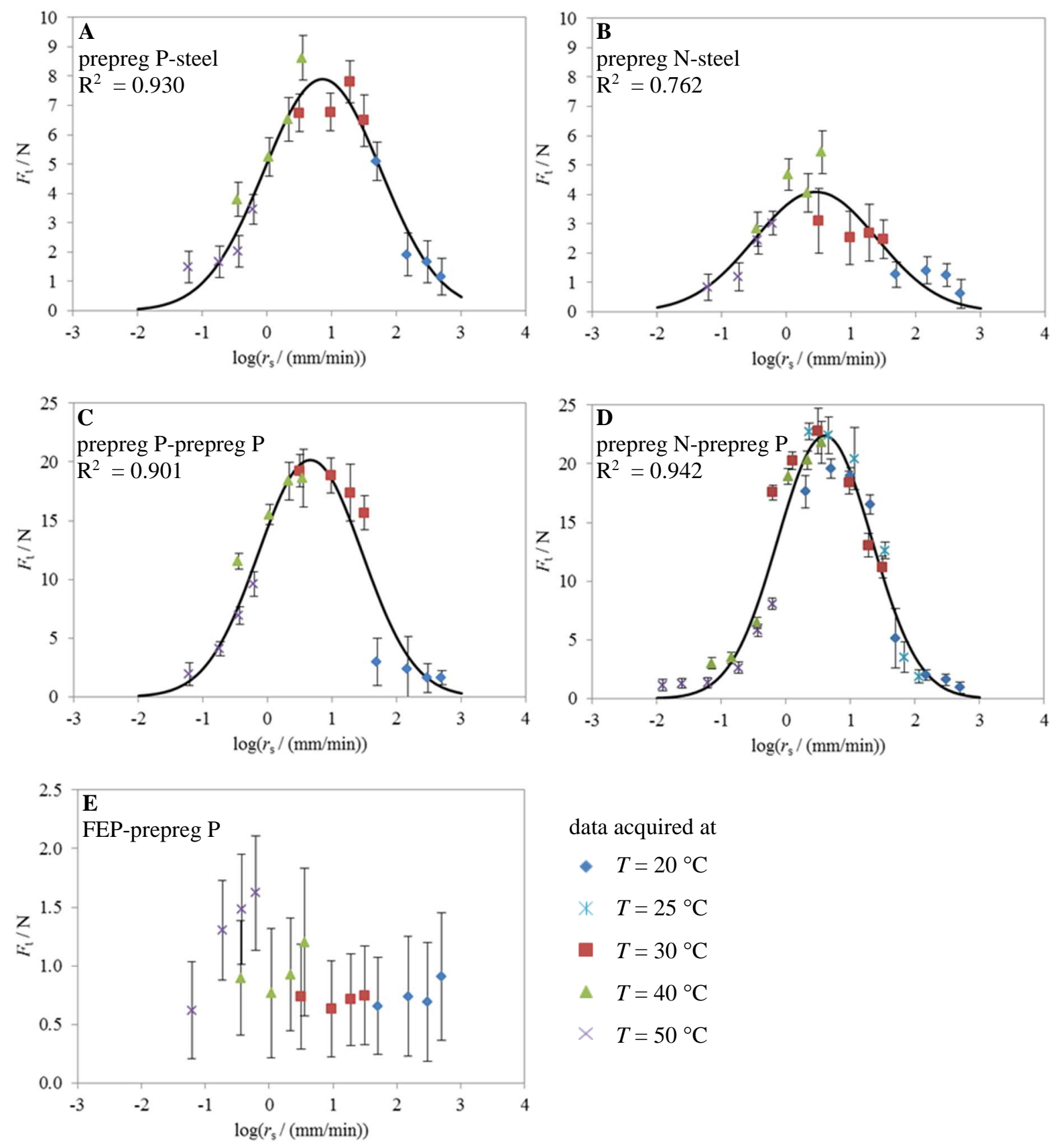

data acquired at

- $T=20^{\circ} \mathrm{C}$

* $T=25^{\circ} \mathrm{C}$

- $T=30^{\circ} \mathrm{C}$

4 $T=40^{\circ} \mathrm{C}$

$\times \quad T=50^{\circ} \mathrm{C}$

Figure 4. Tack data for different surface combinations, acquired at different temperatures, $T$, and feed rates, $r$, shifted to the reference temperature $T_{0}=20^{\circ} \mathrm{C}$ : tack force, $F_{\mathrm{t}}$, as a function of the shifted feed rate, $r_{\mathrm{s}}$; average values and standard deviations are indicated; the lines indicate Gaussian curves according to Eq. (4); coefficients of determination, $\mathrm{R}^{2}$, are also indicated. 

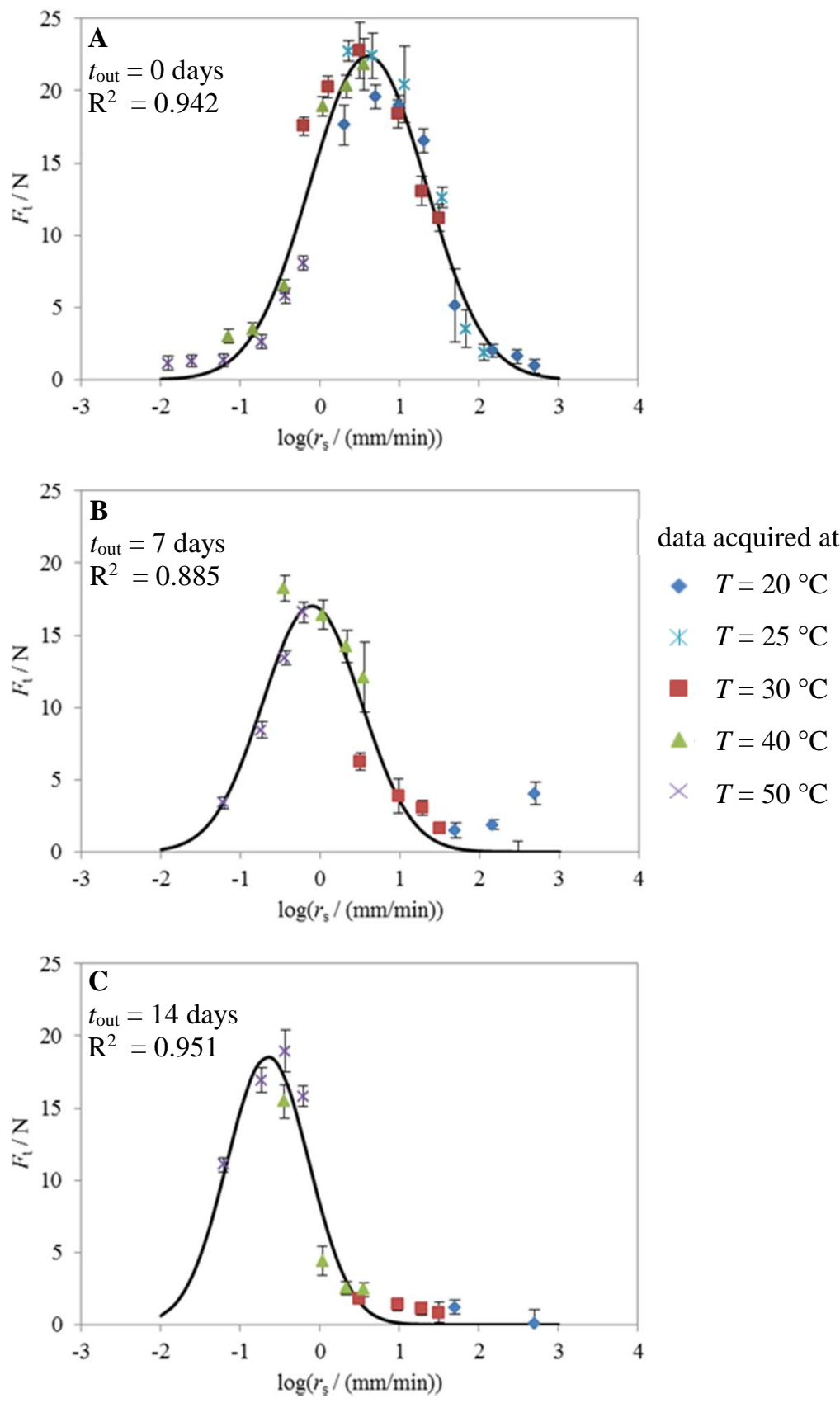

Figure 5. Prepreg-prepreg ( $\mathrm{N}$ face on $\mathrm{P}$ face) tack data at different out-times, $t_{\text {out }}$, acquired at different temperatures, $T$, and feed rates, $r$, shifted to the reference temperature $T_{0}=20{ }^{\circ} \mathrm{C}$; tack force, $F_{\mathrm{t}}$, as a function of the shifted feed rate, $r_{\mathrm{s}}$; average values and standard deviations are indicated; the lines indicate Gaussian curves according to Eq. (4); coefficients of determination, $\mathrm{R}^{2}$, are also indicated. 

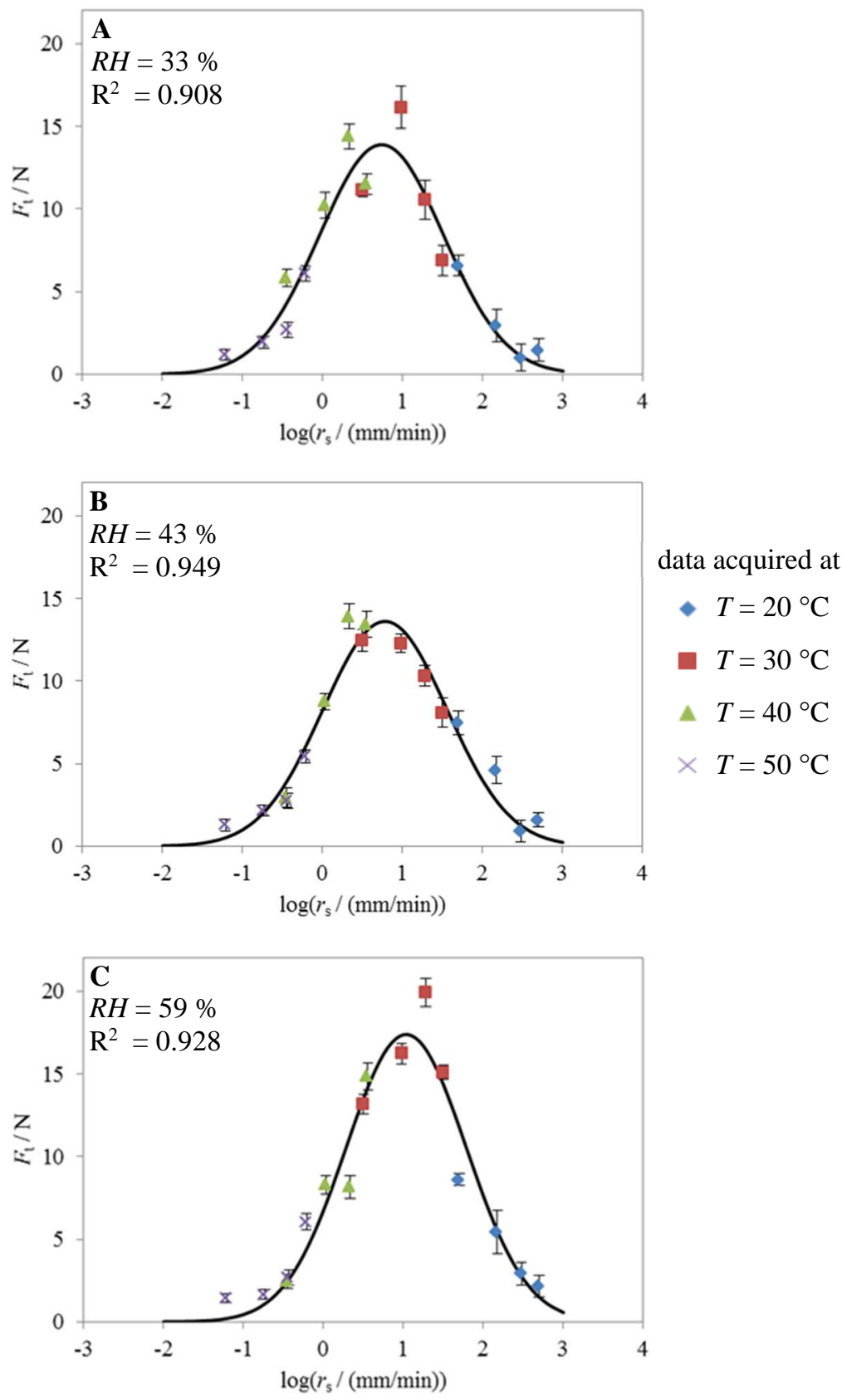

Figure 6. Prepreg-prepreg ( $\mathrm{N}$ face on $\mathrm{P}$ face) tack data at different levels of relative humidity, $R H$, acquired at different temperatures, $T$, and feed rates, $r$, shifted to the reference temperature $T_{0}=20^{\circ} \mathrm{C}$ : tack force, $F_{\mathrm{t}}$, as a function of the shifted feed rate, $r_{\mathrm{s}}$; average values and standard deviations are indicated; the lines indicate Gaussian curves according to Eq. (4); coefficients of determination, $\mathrm{R}^{2}$, are also indicated. 


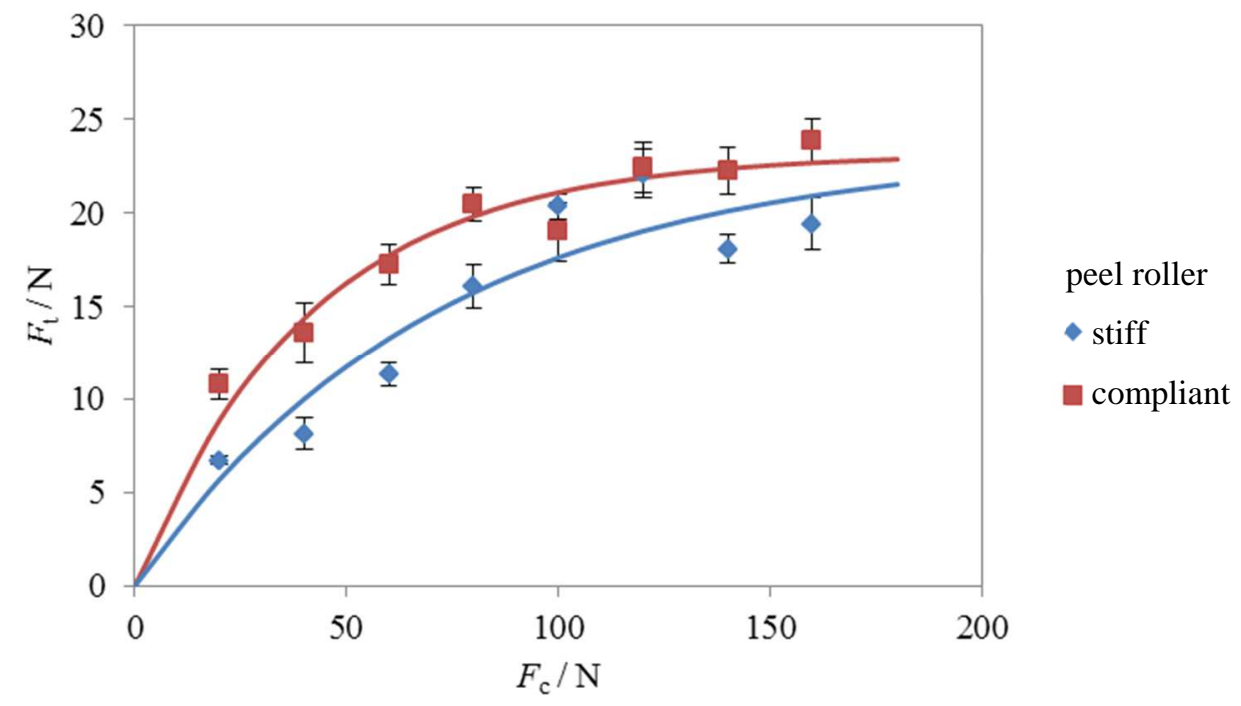

Figure 7. Prepreg-prepreg ( $\mathrm{N}$ face on $\mathrm{P}$ face) tack force, $F_{\mathrm{t}}$, as a function of compaction force, $F_{\mathrm{c}}$, at a temperature $T=30^{\circ} \mathrm{C}$ and feed rate $r=20 \mathrm{~mm} / \mathrm{min}$; experimental data (average values and standard deviations) and fit curves according to Eq. (5).

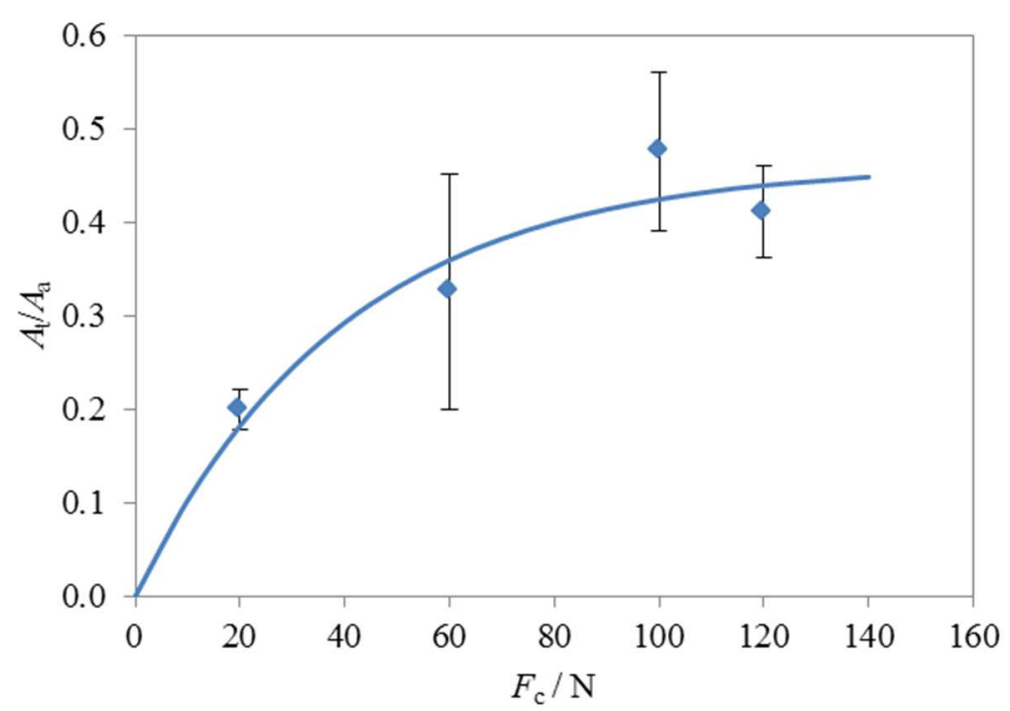

Figure 8. True contact area between prepreg and glass plate, $A_{\mathrm{t}}$, expressed in terms of percentage of apparent contact area, $A_{\mathrm{a}}$, as a function of compaction force, $F_{\mathrm{c}}$ (converted to a specimen width of $75 \mathrm{~mm}$ ), at a temperature $T=21^{\circ} \mathrm{C}$ and feed rate $r=3 \mathrm{~mm} / \mathrm{min}$; average values and standard deviations are given; the line indicates a fit in analogy to Eq. (5). 


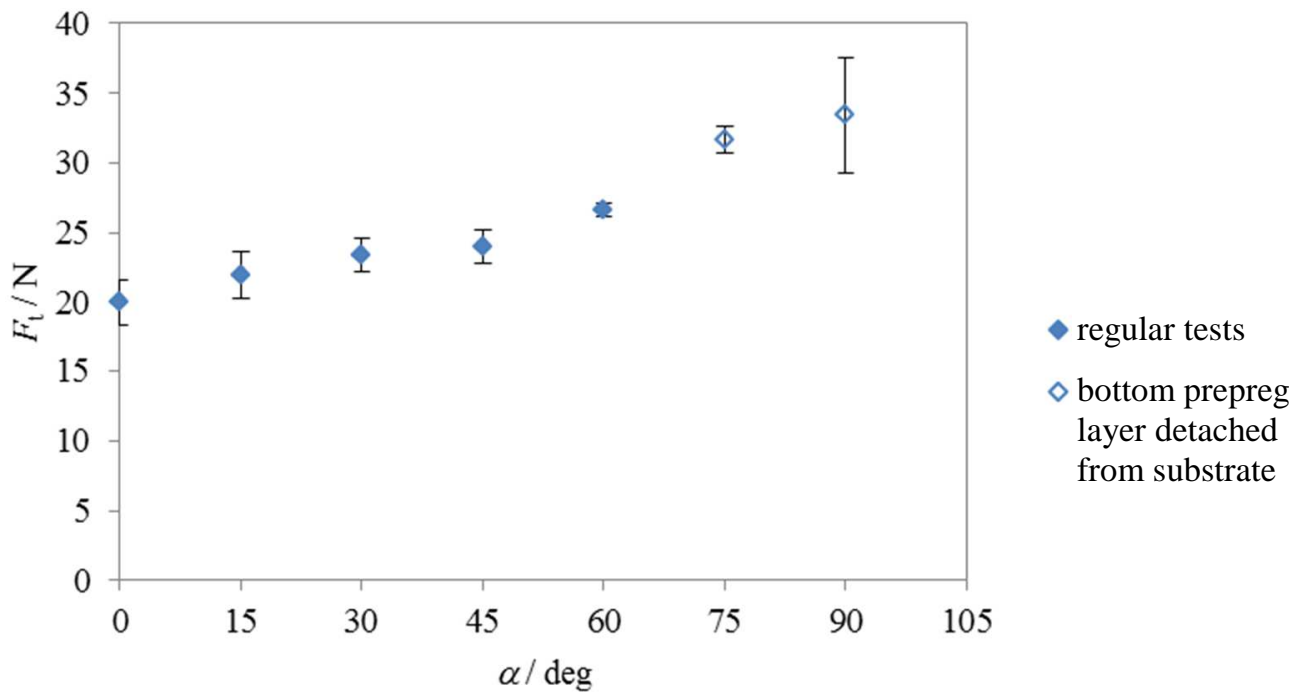

Figure 9. Prepreg-prepreg ( $\mathrm{N}$ face on $\mathrm{P}$ face) tack force, $F_{\mathrm{t}}$, as a function of inter-ply angle, $\alpha$, at a temperature $T=30^{\circ} \mathrm{C}$ and feed rate $r=50 \mathrm{~mm} / \mathrm{min}$; average values and standard deviations are indicated.
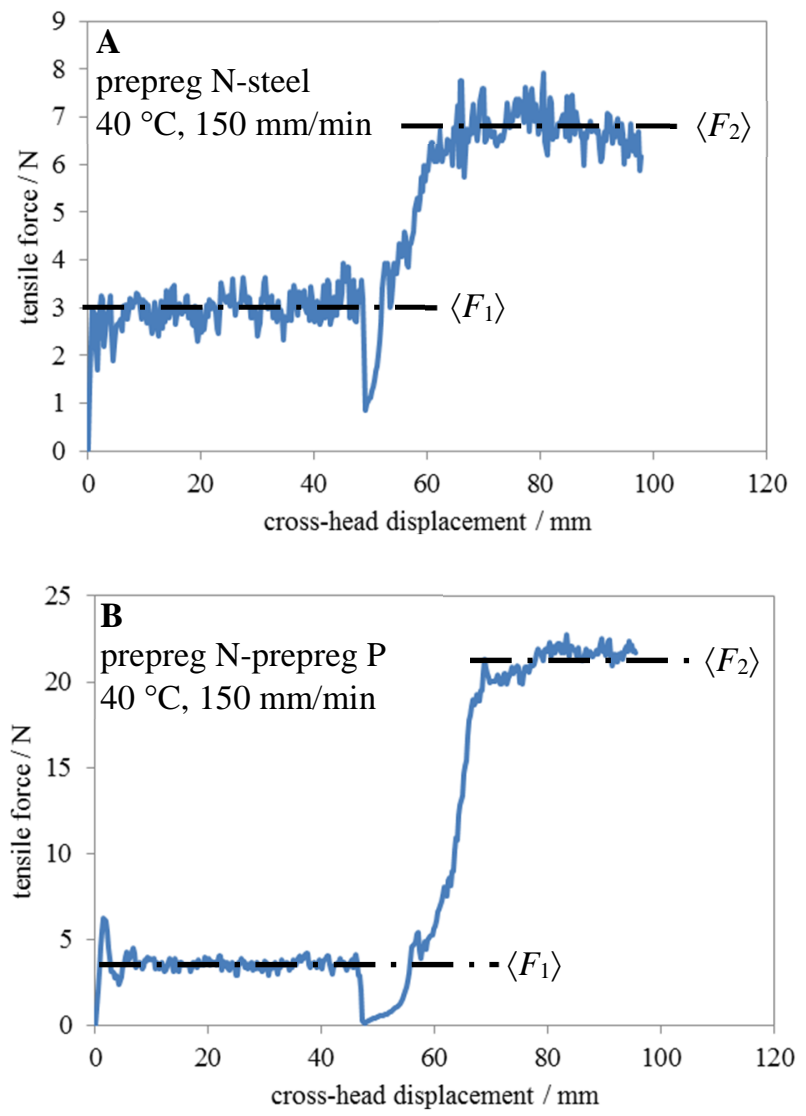

Figure A1. Examples for the measured tensile force as a function of the cross-head displacement during a tack test; the specimen width was $75 \mathrm{~mm}$, the compaction force $100 \mathrm{~N}$. 
Table 1. Tack data for different surface combinations, shifted to a reference temperature $T_{0}=20^{\circ} \mathrm{C}$ : maximum tack force, $F_{\text {tmax }}$, shifted feed rate at maximum tack, $r_{\mathrm{smax}}$, and width of curves, $w$, derived from Gaussian fit curves according to Eq. (4); average values and standard errors are given; coefficients of determination, $\mathrm{R}^{2}$, are also given.

\begin{tabular}{ccccc}
\hline surface combination & $F_{\operatorname{tmax}} / \mathrm{N}$ & $r_{\text {smax }} /(\mathrm{mm} / \mathrm{min})$ & $w$ & $\mathrm{R}^{2}$ \\
\hline prepreg P - steel & $7.90 \pm 0.36$ & $7.14 \pm 0.78$ & $1.28 \pm 0.07$ & 0.930 \\
prepreg N - steel & $4.09 \pm 0.34$ & $2.84 \pm 0.63$ & $1.34 \pm 0.15$ & 0.762 \\
prepreg P - prepreg P & $20.18 \pm 1.24$ & $4.55 \pm 0.60$ & $1.14 \pm 0.09$ & 0.901 \\
prepreg N - prepreg P & $22.41 \pm 0.72$ & $3.98 \pm 0.27$ & $1.03 \pm 0.04$ & 0.942 \\
\hline
\end{tabular}

Table 2. Prepreg-prepreg ( $\mathrm{N}$ face on $\mathrm{P}$ face) tack data for different out-times, $t_{\text {out }}$, shifted to a reference temperature $T_{0}=20^{\circ} \mathrm{C}$ : maximum tack force, $F_{\text {tmax }}$, shifted feed rate at maximum tack, $r_{\text {smax }}$, and width of curves, $w$, derived from Gaussian fit curves according to Eq. (4); average values and standard errors are given; coefficients of determination, $\mathrm{R}^{2}$, are also given.

\begin{tabular}{ccccc}
\hline$t_{\text {out }} /$ days & $F_{\text {tmax }} / \mathrm{N}$ & $r_{\text {smax }} /(\mathrm{mm} / \mathrm{min})$ & $w$ & $\mathrm{R}^{2}$ \\
\hline 0 & $22.41 \pm 0.72$ & $3.98 \pm 0.27$ & $1.03 \pm 0.04$ & 0.942 \\
7 & $17.05 \pm 1.30$ & $0.78 \pm 0.10$ & $0.88 \pm 0.10$ & 0.885 \\
14 & $18.57 \pm 1.10$ & $0.22 \pm 0.02$ & $0.73 \pm 0.06$ & 0.951 \\
\hline
\end{tabular}

Table 3. Specimen mass, $m$, after conditioning at different relative humidity, $R H$, and change in specimen mass, $\Delta m$, compared to specimen after conditioning at $R H=33 \%$.

\begin{tabular}{ccc}
\hline$R H$ & $m / \mathrm{mg}$ & $\Delta m / \mathrm{mg}$ \\
\hline $33 \%$ & 736.26 & $/$ \\
$43 \%$ & 736.71 & 0.45 \\
$59 \%$ & 737.35 & 1.09 \\
\hline
\end{tabular}


Table 4. Prepreg-prepreg ( $\mathrm{N}$ face on $\mathrm{P}$ face) tack data for different target values of the relative humidity, $R H$, shifted to a reference temperature $T_{0}=20^{\circ} \mathrm{C}$ : maximum tack force, $F_{\text {tmax }}$, shifted feed rate at maximum tack, $r_{\text {smax }}$, and width of curves, $w$, derived from Gaussian fit curves according to Eq. (4); average values and standard errors are given; coefficients of determination, $\mathrm{R}^{2}$, are also given.

\begin{tabular}{ccccc}
\hline$R H$ & $F_{\mathrm{tmax}} / \mathrm{N}$ & $r_{\mathrm{s} \max } /(\mathrm{mm} / \mathrm{min})$ & $w$ & $\mathrm{R}^{2}$ \\
\hline $33 \%$ & $13.90 \pm 0.84$ & $5.41 \pm 0.66$ & $1.09 \pm 0.08$ & 0.908 \\
$43 \%$ & $13.62 \pm 0.60$ & $6.01 \pm 0.54$ & $1.10 \pm 0.06$ & 0.949 \\
$59 \%$ & $17.40 \pm 0.97$ & $10.79 \pm 1.17$ & $1.06 \pm 0.07$ & 0.928 \\
\hline
\end{tabular}

Table 5. Constants, $F_{\mathrm{t} \infty}$ and $F_{\mathrm{c}}{ }^{*}$, in Eq. (5) for prepreg-prepreg ( $\mathrm{N}$ face on $\mathrm{P}$ face) tack as a function of the compaction force obtained using different peel rollers at a temperature $T=30{ }^{\circ} \mathrm{C}$ and feed rate $r=20 \mathrm{~mm} / \mathrm{min}$; average values and standard errors are given; coefficients of determination, $\mathrm{R}^{2}$, are also given.

\begin{tabular}{cccc}
\hline roller & $F_{\mathrm{t} \infty} / \mathrm{N}$ & $F_{\mathrm{c}}{ }^{*} / \mathrm{N}$ & $\mathrm{R}^{2}$ \\
\hline compliant & $23.17 \pm 0.95$ & $41.33 \pm 5.54$ & 0.972 \\
stiff & $23.44 \pm 3.37$ & $71.68 \pm 22.89$ & 0.929 \\
\hline
\end{tabular}

Table 6. Relative increase in prepreg-prepreg ( $\mathrm{N}$ face on $\mathrm{P}$ face) tack, $\Delta F_{\mathrm{t}} / F_{\mathrm{t}}\left(\alpha=0^{\circ}\right.$ ), with increasing inter-ply angle, $\alpha$, at a temperature $T=30{ }^{\circ} \mathrm{C}$ and feed rate $r=50 \mathrm{~mm} / \mathrm{min} ;{ }^{+}$indicates tests where bottom prepreg layer detached from steel substrate.

\begin{tabular}{cccccccc}
\hline$\alpha$ & $0^{\circ}$ & $15^{\circ}$ & $30^{\circ}$ & $45^{\circ}$ & $60^{\circ}$ & $75^{\circ}$ & $90^{\circ}$ \\
\hline$\Delta F_{\mathrm{t}} / F_{\mathrm{t}}\left(\alpha=0^{\circ}\right)$ & - & $10 \%$ & $17 \%$ & $20 \%$ & $33 \%$ & $58 \%^{+}$ & $67 \%^{+}$ \\
\hline
\end{tabular}

Table A1. Average values (indicated by brackets) and standard deviations $(\sigma)$ of the forces corresponding to the diagrams in Fig. A1; measured forces during phases 1 and 2 of the tack tests, $F_{1}$ and $F_{2}$, force for bending of one layer of backing paper, $F_{\mathrm{b}}$, and resulting tack force, $F_{\mathrm{t}}$.

\begin{tabular}{ccccccccc}
\hline $\begin{array}{c}\text { surface } \\
\text { combination }\end{array}$ & $\left\langle F_{1}\right\rangle / \mathrm{N}$ & $\sigma_{1} / \mathrm{N}$ & $\left\langle F_{2}\right\rangle / \mathrm{N}$ & $\sigma_{2} / \mathrm{N}$ & $\left\langle F_{\mathrm{b}}\right\rangle / \mathrm{N}$ & $\sigma_{\mathrm{b}} / \mathrm{N}$ & $\left\langle F_{\mathrm{t}}\right\rangle / \mathrm{N}$ & $\sigma_{\mathrm{t}} / \mathrm{N}$ \\
\hline $\begin{array}{c}\text { prepreg N - } \\
\text { steel }\end{array}$ & 3.02 & 0.32 & 6.81 & 0.38 & 0.87 & 0.22 & 4.66 & 0.54 \\
$\begin{array}{c}\text { prepreg N - } \\
\text { prepreg P }\end{array}$ & 3.55 & 0.26 & 21.59 & 0.54 & 0.87 & 0.22 & 18.92 & 0.64 \\
\hline
\end{tabular}

